\title{
Rivoflavin may interfere with on-line monitoring of secreted green fluorescence protein fusion proteins in Pichia pastoris Anna Surribas ${ }^{\dagger}$, David Resina ${ }^{\dagger}$, Pau Ferrer and Francisco Valero*
}

\author{
Address: Departament d'Enginyeria Química. Escola Tècnica Superior d'Enginyeria, Universitat Autònoma de Barcelona, 08193-Bellaterra \\ (Cerdanyola del Vallès), Spain \\ Email: Anna Surribas - anna.surribas@uab.cat; David Resina - david.resina@uab.cat; Pau Ferrer - pau.ferrer@uab.cat; \\ Francisco Valero* - francisco.valero@uab.cat \\ * Corresponding author †Equal contributors
}

Published: 18 May 2007

Microbial Cell Factories 2007, 6:15 doi:10.1 186/1475-2859-6-15
Received: 26 March 2007

Accepted: 18 May 2007

This article is available from: http://www.microbialcellfactories.com/content/6/1/15

(c) 2007 Surribas et al; licensee BioMed Central Ltd.

This is an Open Access article distributed under the terms of the Creative Commons Attribution License (http://creativecommons.org/licenses/by/2.0), which permits unrestricted use, distribution, and reproduction in any medium, provided the original work is properly cited.

\begin{abstract}
Background: Together with the development of optical sensors, fluorometry is becoming an increasingly attractive tool for the monitoring of cultivation processes. In this context, the green fluorescence protein (GFP) has been proposed as a molecular reporter when fused to target proteins to study their subcellular localization or secretion behaviour. The present work evaluates the use of the GFP fusion partner for monitoring extracellular production of a Rhizopus oryzae lipase (ROL) in Pichia pastoris by means of 2D-fluorimetric techniques
\end{abstract}

Results: In this study, the GFP-ROL fusion protein was successfully produced as a secreted fusion form in $P$. pastoris batch cultivations. Furthermore, both the fusion enzyme and the fluorescent protein (GFP S65T mutant) retained their biological activity. However, when multiwavelength spectrofluorometry was used for extracellular fusion protein monitoring, riboflavin appeared as a major interfering component with GFP signal. Only when riboflavin was removed by ultrafiltration from cultivation supernatants, GFP fluorescence signal linearly correlated to lipase activity

Conclusion: $P$. pastoris appears to secrete/excrete significant amounts of riboflavin to the culture medium. When attempting to monitor extracellular protein production in $P$. pastoris using GFP fusions combined with multiwavelength spectrofluorimetric techniques, riboflavin may interfere with GFP fluorescence signal, thus limiting the application of some GFP variants for on-line extracellular recombinant protein quantification and monitoring purposes.

\section{Background}

Development in bioprocess technology requires new monitoring techniques that allow a deeper understanding of the system for better bioprocess control and quality assurance. To cope with these requirements, different monitoring techniques have been developed. Among them, optical technologies present some interesting advantages since they allow non-invasive in vivo monitoring of the bioprocess. Reagents consumption is usually not necessary as there is no sampling or sample pre-treatment and they do offer the possibility of acquiring intracellular versatile information without interferences with cells metabolism.

Fluorometry is being increasingly used in bioprocess monitoring applications due to the development in fluorescence sensors [1-3]. The first generation of optical devices, able to acquire the fluorescence signal at one pair 
of excitation and emission wavelengths, have evolved into multiwavelength devices that can acquire the resultant fluorescence intensity from different fluorophores throughout a cultivation. Over the past years, multiwavelentgh fluorometry has been applied to the monitoring of different compounds in several biological systems $[4,5]$.

In this context, the Aequorea victoria green fluorescence protein (GFP) has attracted a enormous interest as a molecular reporter. GFP has the advantage that its chromophore is formed in an autocatalytic cyclization that does not require a cofactor. Moreover, GFP usually maintains intact the properties of the protein which is fused to. Many applications have been developed using this protein as a reporter of gene expression, protein localization or folding [6]. Also, GFP fusions have been used for on-line monitoring of the product formation with insitu methods in recombinant protein production processes $[5,7,8]$.

The methylotrophic yeast Pichia pastoris has become a well-established system for heterologous protein production. The level of protein expression in P. pastoris depends critically on the growth conditions and, therefore, the online monitoring of product formation in such processes may be an attractive for faster process development and optimisation.

Recently, multiwavelength fluorometry has been applied to the monitoring of $P$. pastoris cultivation processes $[5,9]$. For instance, it has been shown that 2-D fluorometry can be satisfactorily applied to the monitoring of biomass and substrate but that further work should be done to improve foreign protein monitoring [9]. However, only few examples of extracellular expression of GFP or fusion GFP-proteins in $P$. pastoris have been reported, either using the $S$. cerevisiae $\alpha$-mating factor signal peptide $[10,11]$, or alternative secretion factors such as the viral secretion signal derived from the K28 virus preprotoxin [12] and the Phaseolus vulgaris agglutinin secretion signal [13].

The $R$. oryzae lipase (ROL) gene has been previously expressed extracellularly in $P$. pastoris under the control of the formaldehyde dehydrogenase promoter, PFLD1 $[14,15]$. In this work, the GFP protein (S65T variant) has been fused to the ROL gene and expressed in the same system in order to investigate its potential as a reporter for on-line monitoring of extracellular protein production in P. pastoris.

\section{Results and discussion Construction, isolation of transformants and expression studies}

Previous studies on expression of GFP fusions with the lipase 1 from the yeast Candida rugosa in P. pastoris [11] indicated that GFP fusions at the N-terminus of the protein resulted in higher expression levels than when fused to the C-terminus. However, this effect has proven to be case dependent and, therefore, two fusions of the GFP and $R O L$ genes, one with the GFP gene fused at the 5 ' end and one with the GFP gene fused to the 3' end of the ROL gene were constructed by SOE-PCR and inserted into the PPIC$Z F L D \alpha$ expression vector. $P$. pastoris transformants from the PPICZFLD $\alpha$ GFP-ROL and pPICZFLD $\alpha$ ROL-GFP constructions were selected on YPD plates containing zeocin. For each construction, several clones were selected.

Five isolated clones X-33+pPICZFLD $\alpha$ GFP-ROL and three isolated clones X-33+ pPICZFLD $\alpha$ ROL-GFP were precultivated in baffled shake flasks using BMS medium and methylamine as inducing substrate. Secreted recombinant ROL levels in culture supernatants were tested after $48 \mathrm{~h}$. The $P$. pastoris X-33+ pPICZFLD $\alpha$ ROL strain expressing $R O L$ gene under the FLD1 promoter [15] was used as a reference to compare expression levels.

The ROL-GFP transformants showed about 4-fold lower averaged specific activity levels than the GFP-ROL (0.006 $\pm 0.005 \mathrm{AU} \cdot \mathrm{OD}^{-1}$ and $0.023 \pm 0.012 \mathrm{AU} \cdot \mathrm{OD}^{-1}$ respectively). Moreover, in all the tested clones, expression levels of the fusion protein, were at least 10-fold lower than in the cultivation with the control strain expressing ROL $\left(0.284 \pm 0.053 \mathrm{AU} \cdot \mathrm{OD}^{-1}\right)$. These differences in expression levels were confirmed by SDS-PAGE (data not shown). In order to assess the quality of the secreted fusion product, western blot analyses from shake flask samples of both GFP-ROL and ROL-GFP clones were performed after $66 \mathrm{~h}$ of cultivation (figure 1). In both cases, the analyses revealed the presence of a protein of about $60 \mathrm{kDa}$, corresponding to the fusion protein. However, culture supernatant samples from the GFP-ROL producing clones showed an additional band of approximately $30 \mathrm{kDa}$, probably corresponding to the proteolytic cleavage of the fusion product into its two components, GFP and ROL. In contrast, no degradation was observed in samples from ROLGFP producing clones.

The X-33+pPICZFLD $\alpha$ GFP-ROL transformant with the highest specific activity (clone 1.5.5) was selected for further expression studies in bioreactor cultivations.

\section{Monitoring of extracellular GFP fluorescence levels in bioreactor batch cultivations}

A batch cultivation was performed with the selected $P$. pastoris X-33+ pPICZFLD $\alpha$ GFP-ROL clone under bioreactor controlled conditions. A parallel control batch cultivation was performed in baffled shake flasks with the ROLexpressing X-33+pPICZFLD $\alpha$ ROL strain. The evolution of cell density, sorbitol concentration and the lipase activity along the cultivation expressing the fusion protein is 


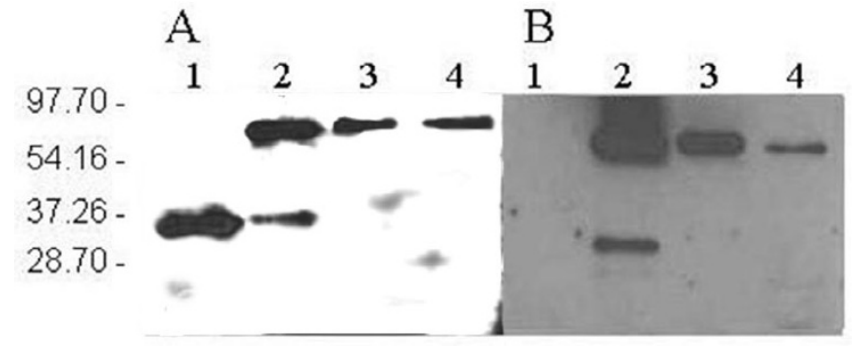

Figure I

Western blot analysis of shake flask and bioreactor batch cultivation samples. Western blots using anti-ROL antibodies (A) and anti-GFP antibodies (B). Lane I: ROL positive control, lane 2: culture supernatant from clone GFPROL I.5.5; lane 3: culture supernatant from clone ROL-GFP 2. I5.2; lane 4: culture supernatant from bioreactor culture of clone GFP-ROL I.5.5.

depicted in figure 2. Sorbitol was added at 73.5 hours of cultivation to further extend cell's growth phase, i.e allowing for higher product levels. Notably, in contrast to the preceding shake flask cultivations, no proteolytic degradation of the secreted fusion product was observed in the corresponding western blot analysis (figure 1, lane 4). Reduced proteolysis may be the result of better controlled cultivation conditions $(\mathrm{pH}$, aeration and substrate) achieved in bioreactor cultures.

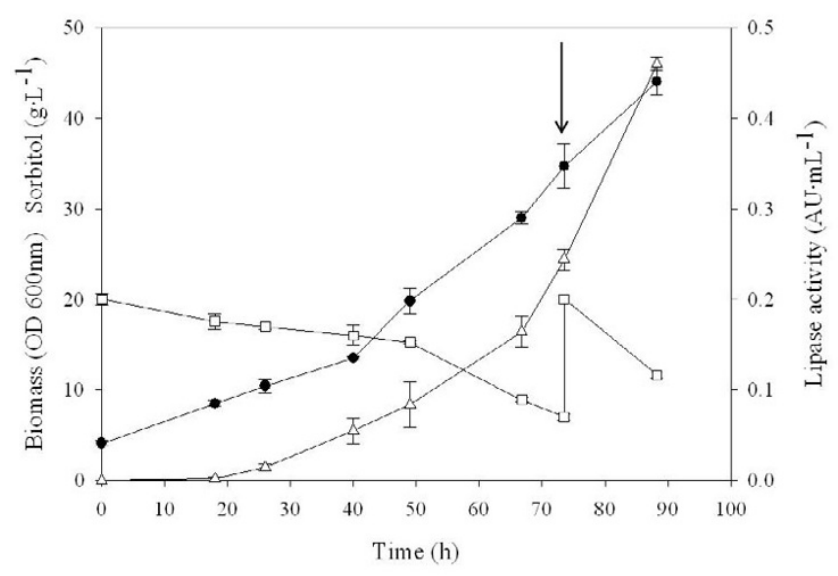

Figure 2

Bioreactor batch culture of clone GFP-ROL I.5.5.

Bioreactor batch cultivation of $P$. pastoris strain expressing the GFP-ROL fusion protein under the control of the FLDI promoter. Sorbitol was used as the carbon source while methylamine was used both as the nitrogen source and protein inducer. Biomass $(\boldsymbol{O})$, sorbitol concentration $(\square)$ and lipase activity $(\triangle)$ are depicted. Arrow indicates the addition of I5 $\mathrm{g} \cdot \mathrm{L}-\mathrm{I}$ of sorbitol.
GFP fusions were evaluated as a potential tool for extracellular protein quantitative on-line monitoring in $P$. pastoris. GFP fluorescence was measured from clarified batch cultivation samples. The emission spectra for culture supernatants excited at $489 \mathrm{~nm}$ were analyzed. A peak appeared at $520 \mathrm{~nm}$ in clarified supernatants from control and GFP fusion cultivations. In both cases, this peak increased along the cultivation time. Preliminary studies (data not shown), corroborated that ROL did not have any fluorescence signal at the tested emission and excitation wavelengths, indicating that neither GFP nor ROL were responsible for the fluorescence emission signal at $520 \mathrm{~nm}$ observed in the supernatant of the control cultivation. This suggested that $P$. pastoris secretes a fluorescent growth-related product with a very similar excitation and emission spectra to the S65T GFP.

Recently [9], multi-wavelength on-line fluorescence measurements have been used to estimate biomass, substrate and heterologous product during a $P$. pastoris cultivation process. Riboflavin (vitamin B2), having an excitation/ emission spectra of $450 / 530 \mathrm{~nm}$, was used for biomass prediction. Riboflavin is a precursor for the synthesis of coenzymes like flavin mononucleotide (FMN) and flavin adenine dinucleotide (FAD), needed as electron acceptors by oxidoreductases. Yeasts such as Candida famata are industrially-employed natural overproducers of riboflavin (more than $20 \mathrm{~g} \cdot \mathrm{L}^{-1}$ ) [16]. Hence, our results suggest that riboflavin fluorescence could be overlapping with GFP signal in culture supernatants. Surprisingly, no significant riboflavin signal was detected in grown cells resuspended in a buffer solution. In order to remove riboflavin from culture supernatant samples, these were ultrafiltrated with a $10 \mathrm{kDa}$ cut-off membrane. Ultrafiltrated and retained fractions were subsequently analyzed by spectrofluorometry. Figure $3 \mathrm{~A}$ shows the retained fraction at $10 \mathrm{kDa}$, while figure $3 \mathrm{~B}$ shows the filtrate fraction, presumably containing riboflavin.

As expected, the filtrate fraction excited at $489 \mathrm{~nm}$ showed a peak at $520 \mathrm{~nm}$, most probably corresponding to riboflavin. Notably, a new peak appeared in the retained fraction excited at the same wavelength, with a maximum at $510 \mathrm{~nm}$, in concordance with the GFP emission spectrum. This indicated that the extracellular GFP fluorescence could be efficiently measured in clarified culture supernatant samples after the ultrafiltration step. Also, the effect of the cultivation medium on GFP fluorescence was tested by resuspending the retained fraction from clarified batch cultivation supernatant samples in two different media: the fresh cultivation medium used for batch processes or, alternatively, $50 \mathrm{mM}$ phosphate buffer, $\mathrm{pH}$ 7.0. The emission spectra of both samples revealed that GFP fluorescent signal is weaker under growth medium conditions (data not shown), due to the lower $\mathrm{pH}$ of medium ( $\mathrm{pH} 5.5$ ) 

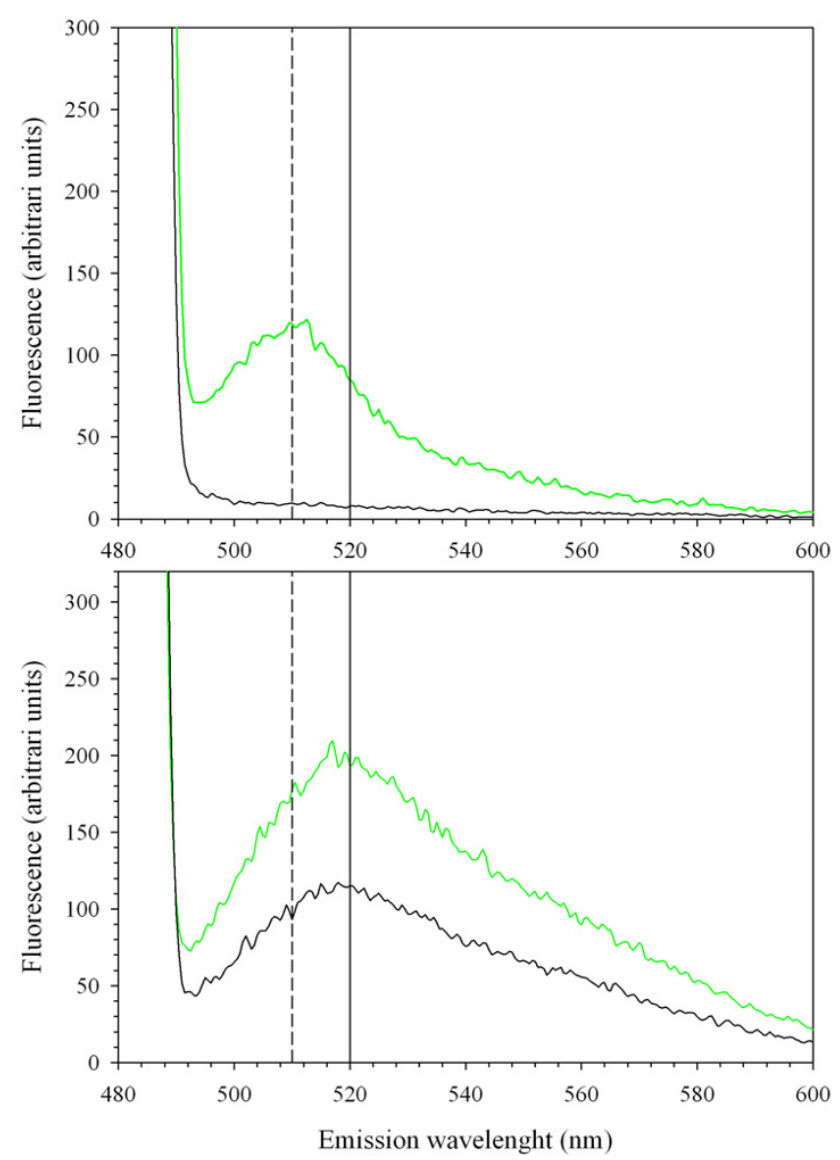

Figure 3

Emission spectrum from retained and filtered culture supernatans. Emission spectrum, given as fluorescence arbitrary units, excited at $488 \mathrm{~nm}$ from control strain cultivation samples (black) and GFP-fusion expressing strain cultivation samples (green line). Retained fractions $(A)$, and corresponding filtrated fractions (B).

with respect to phosphate buffer. This effect has also been described for the GFP S65T mutant [17].

Importantly, extracellular GFP fluorescence and lipase activity from ultrafiltred samples were linearly correlated (figure 4), i.e. showing the potential of GFP fusions for on-line quantitative monitoring of ROL secretion in $P$. pastoris using fluorometric techniques, even in the case where secreted product titers may be low.

\section{Conclusion}

In this work, the cloning and expression of a GFP-ROL fusion protein has been successfully achieved. A series of shake flask experiments and one batch bioreactor cultivation has been performed to test the fusion protein expression levels, as well as the feasibility to apply

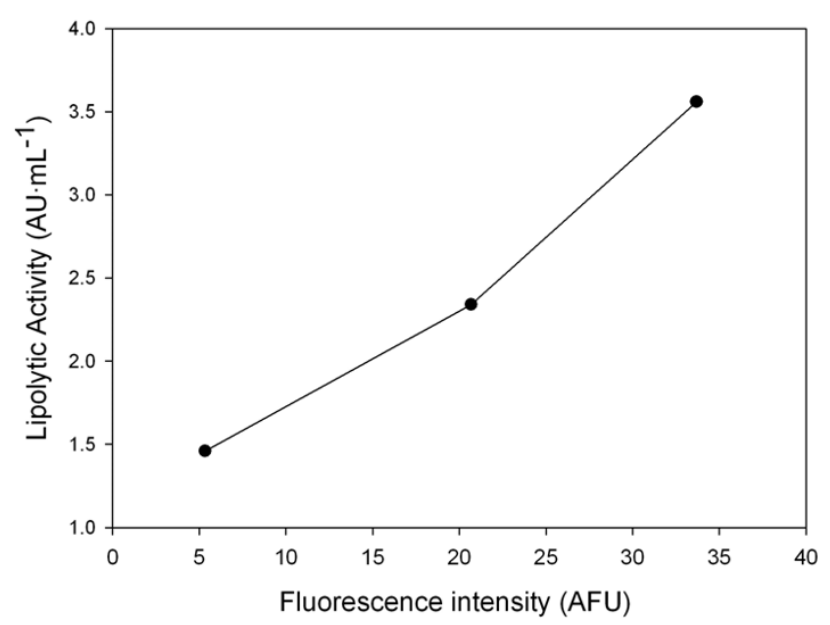

Figure 4

Lipase activity versus GFP fluorescence correlations in ultrafiltrated culture supernatants. Correlation between the measured lipolytic activity and the relative fluorescence in ultrafiltrated culture samples (0). Excitation and emission wavelengths were $489 \mathrm{~nm}$ and $510 \mathrm{~nm}$ respectively.

multiwavelength fluorometry for on-line quantitative monitoring of product secretion.

Notably, the fusion of GFP to ROL provoked a 10-fold decrease in extracellular lipase production levels in relation to the values obtained with the non-fused ROL construct. A reduction of expression levels when fusing GFP to target proteins has also been reported for other cases in $P$. pastoris [11] and S. cerevisiae [18]. In this context, significant levels of intracellular GFP-ROL fusion product have been detected in P. pastoris cells by flow cytometry and confocal microscopy techniques [19], pointing to the transport step as a major bottleneck and possibly explaining the lower extracellular product levels. Intracellular accumulation of GFP into subcellular organelles has been previously described $[18,20]$.

When attempting to measure the extracellular GFP-ROL fusion by fluorometry, we observed that a $P$. pastoris growth-related product, probably riboflavin, overlapped the GFP signal. Only when riboflavin was removed from samples by ultrafiltration, the GFP signal could be detected in the clarified supernatants samples. Also, lipolytic activity was in good correlation with extracellular GFP fluorescence, which indicates that the GFP fusion protein was actively secreted into the medium and could be used as reporter for extracellular recombinant protein expression. Nevertheless, ultrafiltration techniques may not be readily applied to overcome such interference in on-line in situ fluorimetric measurements. 
Overall, the efficient use of the GFP variant used in this work for on-line monitoring of extracellular recombinant protein expression in $P$. pastoris poses several limitations, which need to be considered. Other variants such as red shifted mutants or those with excitation wavelengths around $395 \mathrm{~nm}$, such as GFPuv [10], might be a better option to avoid possible interferences with riboflavin or other cellular components and products. Although the decrease in the extracellular production levels would eventually hamper the application of the GFP-ROL fusion as an on-line monitoring tool, it still offers the benefit of a faster and simple detection of potential intracellular product accumulation. In addition, the use of an appropriate improved GFP mutant should avoid the riboflavin interference, i.e. allowing for both intra and extracellular product detection purposes. Altogether, these advantages can be used in the screening optimization of the ROL producing process conditions.

\section{Methods}

\section{Strains}

E. coli DH5 $\alpha$ was used for plasmid construction and amplification. The wild-type phenotype $P$. pastoris X-33 strain (Invitrogen Co., CA, USA) was used as the host strain for the expression of a $R$ oryzae lipase gene $(R O L)$ fused to the Aequoria victoria GFP S65T variant under the transcriptional control of the PFLD1 promoter. The X-33/ pPICZFLD $\alpha$ ROL derivative strain was used for comparative studies [15]. The S65T GFP mutant was used in this work due to its brighter fluorescence and its higher stability compared to the wild type form [6].

\section{Plasmid and strain construction}

Two constructions coding for the fusion protein were performed, one coding for GFP protein fused to the ROL Nterminal end and the other fused to the ROL C-terminal. The constructions ROL-GFP and GFP-ROL were obtained by SOE-PCR [26]. The primers used for each reaction are summarized in table 1 . The construction involved two steps: first, the two genes were separately amplified introducing a 12 amino acid linker between the two sequences $[11,21]$. The GFP gene was amplified from the plasmid pPICZ-GFP [11]. For the GFP-ROL fusion, the forward primer DR9 and the reverse primer DR3 were used for amplification of GFP. Primer DR9 introduced a XhoI restriction site at the $5^{\prime}$ of the sequence for further cloning of the construct into the expression plasmid. Primer DR3 introduced a linker sequence codifying for 12 amino acids (marked in italics in table 1). For ROL amplification, the plasmid pPICZFLDo_ROL [14] was used as template. Primers DR4 and DR2 were used for PCR, primer DR4 contained the linker sequence (in italics) and primer DR2 a restriction site for NotI.
For ROL-GFP fusion, first DR12 and DR6 were utilized for ROL amplification. DR12 contained a XhoI restriction sequence and DR6 introduced a linker sequence identical to the used for GFP-ROL fusion, showed in italics (table 1). GFP was also amplified using the primers DR7 and DR13. DR7 included the linker sequence and DR13 introduced a restriction site for the NotI enzyme.

In a second step, PCR products containing the GFP and ROL genes were fused using the complementary linker regions as PCR primers. In the third step, primers DR14 and DR15 were added into the reaction tube to amplify the product of the SOE-PCR for the ROL-GFP fusion, DR10 and DR11 were utilized in GFP-ROL reaction.

The resulting fusion DNA fragments, GFP-ROL and ROLGFP, both consisting of 1613 base pairs, were cut with XhoI and NotI and ligated into XhoI- and NotI-digested pPICZFLD $\alpha$ backbone. The DNA ligation reaction was then transformed into $E$. coli and transformants were selected on low-salt LB plates containing zeocin. Plasmidic DNA was extracted from several colonies and sequenced for confirmation of the correct fused sequences. The obtained expression vectors for each of the constructions were linearized and used for transformation of $P$. pastoris X-33 competent cells by electroporation [22]. $P$. pastoris transformants from GFP-ROL and ROL-GFP constructions were selected on YPD plates containing zeocin. For each construction four clones were selected and re-inoculated on fresh selective plates for three successive passages to ensure the isolation of pure transformant colonies.

\section{Media composition}

E. coli strains were cultivated in low salt Luria broth (LB) medium, $1 \%(\mathrm{w} / \mathrm{v})$ yeast extract, $1 \%(\mathrm{w} / \mathrm{v})$ peptone and $0.5 \%(\mathrm{w} / \mathrm{v}) \mathrm{NaCl}$ supplemented with $50 \mu \mathrm{g} \mathrm{mL}^{-1}$ zeocin (Invitrogen Co., CA, USA) when necessary. P. pastoris strains were cultivated in YPD medium $(1 \%(\mathrm{w} / \mathrm{v})$ yeast extract, $2 \%(\mathrm{w} / \mathrm{v})$ peptone, $2 \%(\mathrm{w} / \mathrm{v})$ glucose) and 100 $\mu \mathrm{g} \cdot \mathrm{mL}^{-1}$ of zeocin, when required.

Shake flask cultivations were performed using Buffered Minimal Sorbitol medium (BMS) containing 1\% (w/v) sorbitol, $1.34 \%(\mathrm{w} / \mathrm{v})$ YNB without aminoacids and ammonium sulphate, $0.4 \%(\mathrm{w} / \mathrm{v})$ methylamine hydrochloride, $4 \cdot 10^{-5} \%(\mathrm{w} / \mathrm{v})$ biotin and $100 \mathrm{mM}$ potassium phosphate $\mathrm{pH}$ 6.0.

Bioreactor batch cultivations were carried out using a mineral medium [23] with the following composition: $\mathrm{KH}_{2} \mathrm{PO}_{4} 4.8 \mathrm{~g} \cdot \mathrm{L}^{-1}, \mathrm{MgSO}_{4} \cdot 7 \mathrm{H}_{2} \mathrm{O} 1.88 \mathrm{~g} \cdot \mathrm{L}^{-1}, \mathrm{CaCl}_{2} \cdot 2 \mathrm{H}_{2} \mathrm{O}$ $0.144 \mathrm{~g} \cdot \mathrm{L}^{-1}$, sorbitol $20 \mathrm{~g} \cdot \mathrm{L}^{-1}$, methylamine chloride 6 $\mathrm{g} \cdot \mathrm{L}^{-1}, 0.1 \mathrm{~mL} \cdot \mathrm{L}^{-1}$ of antifoam Mazu DF $7960,1 \mathrm{~mL} \cdot \mathrm{L}^{-1}$ of a biotin solution $\left(400 \mathrm{mg} \cdot \mathrm{L}^{-1}\right)$, and $1 \mathrm{~mL} \cdot \mathrm{L}^{-1}$ of trace salts 
Table I: Primers used for SOE-PCR

\begin{tabular}{lc}
\hline Name & Sequence \\
\hline DR2 & gtagagcggccgccaaacagcttccttcgttgatatcaaagtaactca \\
DR3 & aaattcaccagaaccagcagaaccagcagaaccttgtatagttcatccatgccatgtgtaatccc \\
DR4 & ccaagacgaccaagacgaccaagaccacttaaatctgatggtggtaaggttgttgctgctactactg \\
DR6 & aaattcaccagaaccagcagaaccagcagaacccaaacagcttccttcgttgatatca \\
DR7 & ggttctgctggttctgctggttctggtgaatttagtaaaggagaagaactttcactggagt \\
DR9 & ctctcgagaaagagaggctgaagctgaattcatgagtaaaggagaagaactttca \\
DRI0 & gtatctctcgagaaaagagaggctgaagctagtaaaggagaagaactt \\
DRI1 & gcggccgcttattacaaacagcttccttcgttgatatca \\
DRI2 & gtatctctcgagaaaagagaggctgaagcttctgatggtggtaaggtt \\
DRI3 & gcggccgcttattatttgtatagttcatccatgccatgtg \\
DRI4 & gtatctctcgagaaaagagaggctgaagct \\
DRI5 & gcggccgcttattatttgtatagttcatc \\
\end{tabular}

solution $\left(0.2 \mathrm{mM} \mathrm{CuSO}_{4} \cdot 5 \mathrm{H}_{2} \mathrm{O}, 1.25 \mathrm{mM} \mathrm{KI}, 4.5 \mathrm{mM}\right.$ $\mathrm{MnSO}_{4} \cdot 4 \mathrm{H}_{2} \mathrm{O}, 2 \mathrm{mM} \mathrm{Na}_{2} \mathrm{MoO}_{4} \cdot 2 \mathrm{H}_{2} \mathrm{O}, 0.75 \mathrm{mM} \mathrm{H}_{3} \mathrm{BO}_{3}$, $\left.17.5 \mathrm{mM} \mathrm{ZnSO}_{4} \cdot 7 \mathrm{H}_{2} \mathrm{O}, 44.5 \mathrm{mM} \mathrm{FeCl}_{3} \cdot 6 \mathrm{H}_{2} \mathrm{O}\right)$. The biotin and trace salts components were sterilised separately by micro filtration. The starter cultures for bioreactor cultivations were grown in YPD medium.

\section{Cultivation conditions}

Shake flask cultivations were carried out at a working volume of $50 \mathrm{~mL}$ in $500 \mathrm{~mL}$ shake flasks. Cultivations were incubated at $30^{\circ} \mathrm{C}$ and $200 \mathrm{rpm}$. A starter culture of 200 mL grown on YPD medium was used to inoculate the 1.5 L bioreactor culture. Cells were harvested by centrifugation and resuspended in sterile water prior to inoculation. Bioreactor batch cultivation was performed at a working volume of $1.5 \mathrm{~L}$ in a $2 \mathrm{~L}$ bench-top bioreactor (Biostat $\mathrm{B}$, Braun Biotech) at $30^{\circ} \mathrm{C}$ and $800 \mathrm{rpm}$. The $\mathrm{pH}$ of the cultivation was maintained at 5.5 by automatically adding 5 $\mathrm{M} \mathrm{KOH}$. The airflow was kept at $2 \mathrm{~L} \cdot \mathrm{min}^{-1}$, assuring a minimal dissolved oxygen concentration of $30 \%$ throughout the cultivation time.

\section{Analytical procedures}

Cell density was analysed by measuring the optical density at $600 \mathrm{~nm}$. Sorbitol concentration was determined by a HP 1050 liquid chromatograph (Hewlett Packard) and an Aminex HPX-87H ion-exchange column from BioRad. The mobile phase was $15 \mathrm{mM}$ sulphuric acid. Data were quantified by the Millenium 2.15.10 software (Waters Corporation) being $3 \%$ the obtained relative standard deviation.

Lipolytic activity determination was carried out using the Lipase colorimetric assay (kit 1821792 from Roche Diagnostics) [15] with a relative standard deviation of $10 \%$. Intracellular lipase activity (defined as the soluble fraction of the cell bound lipase activity) was measured from clarified supernatants from cell lysates [14].

\section{Fluorescence measurements}

GFP fusion protein fluorescence in culture supernatant and cells samples were measured using a Perkin Elmer LS55 Spectrophotometer (PerkinElmer Ltd., Beaconsfield, UK) equipped with a xenon lamp. For intracellular GFP and cellular autofluorescence, cells were centrifuged at $12,000 \mathrm{rpm}$ using a bench-top centrifuge (Biofuge Fresco Refrigerated Microcentrifuge, Heraeus, Thermo Electron LED GmbH, Langenselbold, Germany). Supernatants were removed for subsequent analyses. To avoid excitation light interferences, cells were excited at $460 \mathrm{~nm}$, while supernatant were analysed at $489 \mathrm{~nm}$. An excitation wavelength of $460 \mathrm{~nm}$ allowed for a better visualization of GFP intracellular fluorescence in intact cells, since using the optimal $480 \mathrm{~nm}$ excitation wavelength resulted in a partial overlap of GFP fluorescence by the excitation light. Emission fluorescence was collected over a range from 480 to $600 \mathrm{~nm}$. Analyses were carried out maintaining the cuvette at $20^{\circ} \mathrm{C}$. When necessary, $50 \mathrm{mM}$ phosphate buffer, pH 7.0 was used to dilute samples. Once emission fluorescence scan was acquired, the maximum emission intensity was measured and used for calculations. Emission maxima were situated at $510 \mathrm{~nm}$ and $520 \mathrm{~nm}$ for the GFP and presumed riboflavin signal, respectively. Ultrafiltration units (Amicon Ultra-15 centrifugal filters, Millipore, MA, USA) with a $10 \mathrm{kDa}$ cut-off membrane were utilized to separate the fusion protein from low molecular weight supernatant components.

\section{SDS-PAGE and Western blot analyses}

Sodium dodecyl sulphate-polyacrilamide (12\%) gel electrophoresis (SDS-PAGE) analyses were performed in a Mini-Protean II unit (Bio-Rad, CA, USA). Western blots were carried out after protein transference from SDSPAGE to a nitrocellulose membrane using a Mini TransBlot Electrophoretic Tranfer Cell (BioRad, CA, USA) following manufacturer's instructions. For ROL detection, a mouse anti-ROL antiserum [14] was used with a dilution 
1:100. For GFP detection, a mouse anti-GFP (Sigma, St. Louis, USA) was used with a dilution 1:500. Antimouse and antirabbit IgG horseradish peroxidase conjugate (Sigma, St. Louis, USA) were used to a 1:1000 dilution as secondary antibody for ROL and GFP detection, respectively. Detection was carried out with the chemiluminescent substrate SuperSignal West Pico (Pierce, IL, USA) and the signal collected by a photographic film. Prior to western blot analyses, samples from shake flask cultivations were concentrated 10-fold using the Amicon Ultra-15 centrifugal filters units (Millipore, MA, USA).

\section{Authors' contributions}

AS and DR carried out the strains construction tasks, expression studies and fluorescence measurements. Together with, PF and FV they collaborated in the results discussion and manuscript preparation. PF and FV supervised the study and participated in the design of experiments and discussion of results.

\section{Acknowledgements}

Authors would like to thank Stefannia Brocca and Marina Lotti from the Dipartamento di Biotecnologie e Bioscienze, Università degli studi di Milano-Bicocca for the kind donation of the $\mathrm{gP}(\mathrm{S} 65 \mathrm{~T})$ gene. This work was supported by the CTQ2004-00300 of the Spanish Ministry of Science and Education (MEC). AS and DR would like to thank the Spanish MEC for their Ph.D. fellowships. The results presented here were communicated at the $4^{\text {th }}$ Recombinant Protein Production Meeting (Barcelona, 2006).

\section{References}

I. Kwong SCW, Randers L, Rao G: Consistency evaluation of batch fermentations based on online NADH fluorescence. Biotechnology Progress 1992, 8:410-4I2.

2. Marose S, Lindemann C, Scheper T: Two-dimensional fluorescence spectroscopy: A new tool for on-line bioprocess monitoring. Biotechnology Progress 1998, I4:63-74.

3. Skibsted E, Lindemann C, Roca C, Olsson L: On-line bioprocess monitoring with a multi-wavelength fluorescence sensor using multivariate calibration. Journal of Biotechnology 200I, 88:47-57.

4. Clementschitsch F, Bayer K: Improvement of bioprocess monitoring: development of novel concepts. Microbial cell factories 2006, 5:19.

5. Hisiger S, Jolicoeur M: A multiwavelength fluorescence probe: Is one probe capable for on-line monitoring of recombinant protein production and biomass activity? Journal of Biotechnology 2005, I I 7:325-336.

6. Zimmer M: Green fluorescent protein (GFP): Applications, structure, and related photophysical behavior. Chemical Reviews 2002, 102:759-781.

7. Reischer H, Schotola I, Striedner G, Potschacher F, Bayer K: Evaluation of the GFP signal and its aptitude for novel on-line monitoring strategies of recombinant fermentation processes. Journal of Biotechnology 2004, I 08: I I5-I 25.

8. Jones JJ, Bridges AM, Fosberry AP, Gardner S, Lowers RR, Newby RR, James PJ, Hall RM, Jenkins O: Potential of real-time measurement of GFP-fusion proteins. Journal of Biotechnology 2004, 109:201-2II.

9. Surribas A, Geissler D, Gierse A, Scheper T, Hitzmann B, Montesinos $\mathrm{J}$, Valero F: State variables monitoring by in situ multi-wavelenght fluorescence spectroscopy in heterologous protein production by Pichia pastoris. Journal of Biotechnology 2006, I 24:412-4I9.

10. Cha HJ, Shin HS, Lim HJ, Cho HS, Dalal NN, Pham MQ, Bentley WE: Comparative production of human interleukin-2 fused with green fluorescent protein in several recombinant expression systems. Biochemical Engineering Journal 2005, 24:225-233.

II. Passolunghi S, Brocca S, Cannizzaro L, Porro D, Lotti M: Monitoring the transport of recombinant Candida rugosa lipase by a green fluorescent protein-lipase fusion. Biotechnology Letters 2003, 25: 1945-1948.

12. Eiden-Plach A, Zagorc T, Heintel T, Carius Y, Breinig F, Schmitt MJ: Viral preprotoxin signal sequence allows efficient secretion of green fluorescent protein by candida glabrata, Pichia pastoris, Saccharomyces cerevisiae, and Schizosaccharomyces pombe. Applied and Environmental Microbiology 2004, 70:961-966.

13. Raemaekers RJM, de Muro L, Gatehouse IA, Fordham-Skelton AP. Functional phytohemagglutinin (PHA) and Galanthus nivalis agglutinin (GNA) expressed in Pichia pastoris - Correct Nterminal processing and secretion of heterologous proteins expressed using the PHA-E signal peptide. European Journal of Biochemistry 1999, 265:394-403.

14. Resina D, Cos O, Ferrer P, Valero F: Developing high cell density fed-batch cultivation strategies for heterologous protein production in Pichia pastoris using the nitrogen source-regulated FLDI promoter. Biotechnology and Bioengineering 2005, 9 I:760-767.

15. Resina D, Serrano A, Valero F, Ferrer P: Expression of a Rhizopus oryzae lipase in Pichia pastoris under control of the nitrogen source-regulated formaldehyde dehydrogenase promoter. Journal of Biotechnology 2004, I09: I03-I I3.

16. Stahmann KP, Revuelta JL, Seulberger H: Three biotechnical processes using Ashbya gossypii, Candida famata, or Bacillus subtilis compete with chemical riboflavin production. Applied Microbiology and Biotechnology 2000, 53:509-5I6.

17. Patterson GH, Knobel SM, Sharif WD, Kain SR, Piston DW: Use of the green fluorescent protein and its mutants in quantitative fluorescence microscopy. Biophysical Journal 1997, 73:2782-2790.

18. Li JC, Xu HX, Bentley WE, Rao G: Impediments to secretion of green fluorescent protein and its fusion from Saccharomyces cerevisiae. Biotechnology Progress 2002, 18:83।-838.

19. Resina D: Expression of the Rhizopus oryzae lipase in Pichia pastoris under the control of the FLDI promoter. PhD Thesis 2006.

20. Zupan AL, Trobec S, Gaberc-Porekar V, Menart V: High expression of green fluorescent protein in Pichia pastoris leads to formation of fluorescent particles. Journal of Biotechnology 2004, 109:115-122.

21. Waldo GS, Standish BM, Berendzen J, Terwilliger TC: Rapid protein-folding assay using green fluorescent protein. Nature Biotechnology 1999, 17:691-695.

22. Cregg JM, Russell KA: Transformation. In Pichia protocols Edited by: Higgins DR, Cregg JM. London: Humana Press; 1989.

23. d'Anjou MC, Daugulis AJ: A rational approach to improving productivity in recombinant Pichia pastoris fermentation. Biotechnology and Bioengineering 200I, 72: I-II.
Publish with Biomed Central and every scientist can read your work free of charge

"BioMed Central will be the most significant development for disseminating the results of biomedical research in our lifetime. "

Sir Paul Nurse, Cancer Research UK

Your research papers will be:

- available free of charge to the entire biomedical community

- peer reviewed and published immediately upon acceptance

- cited in PubMed and archived on PubMed Central

- yours - you keep the copyright 